\title{
A PRESENÇA DA BIBLIOTECA UNIVERSITÁRIA NAS MÍDIAS SOCIAIS: UM ESTUDO BASEADO NO SISTEMA DE BIBLIOTECAS DA UFRJ ${ }^{1}$
}

\author{
Cláudia Regina dos Anjos \\ Universidade Federal do Rio de Janeiro \\ Mestre em Biblioteconomia \\ cranjos@gmail.com
}

\section{Resumo}

Este trabalho investigou o uso das mídias sociais em trinta e uma bibliotecas da Universidade Federal do Rio de Janeiro para compreender como utilizam estas ferramentas e tecer orientações para o bom uso das ferramentas de monitoramento no cenário biblioteconômico. O estudo baseou-se em técnicas de observação e de entrevistas para averiguar a percepção de bibliotecários e usuários na utilização das mídias no contexto das bibliotecas acadêmicas. Embora a importância da comunicação nesse canal seja reconhecida por ambos entrevistados, como meio de promover serviços e produtos, os resultados indicaram que as mídias sociais não são elementos dominantes do universo das bibliotecas acadêmicas.

Palavras-chave: Mídias sociais. Facebook. Twitter. Bibliotecas Universitárias. Web 2.0.

\section{INTRODUÇÃO}

Percorrendo a história da humanidade, descobre-se que várias foram as formas de pensar e usar as bibliotecas. Na Idade Média, as bibliotecas eram basicamente secretas e tidas como verdadeiros tesouros, locais sagrados ou depósitos de coleções, acessíveis apenas a uma minoria religiosa. Esta situação foi modificada pela invenção da prensa de tipos móveis, quando o conhecimento começou a ser levado a um público maior e essas organizações deixaram de ser tesouros particulares para se tornarem serviços, adquirindo um sentido social, consolidando na sociedade a noção que biblioteca é um espaço que fornece acesso à informação (MARTINS, 1996; MILANESI, 1993). Melo (2004) observa que no passado a qualidade dos serviços da biblioteca era dada em função do tamanho da coleção, mas hoje está ligada com os serviços prestados por esta.

Nesse contexto, chama-se atenção para as ferramentas sociais da Web 2.0 - termo cunhado por O' Reilly em 2004, quando se organizou a primeira conferência sobre o assunto (PEREIRA; CARVALHO, 2012) - cuja filosofia prima por promover facilidade de publicação de informações, interatividade e colaboração proporcionada pelos aplicativos de mídia social, tais como Google Drive, Google +, Wikipédia, YouTube, Flickr, WordPress, Blogger, Skype, My Space, Facebook, Twitter, LinkedIn entre outros (SCHONS; RIBEIRO; BATTISTI (2008); BRITO; SILVA (2010). Uma das diferenças mais significativas entre Web 2.0 e Web 1.0 é a comunicação entre os usuários de Internet em relação ao conteúdo. $\mathrm{Na}$ Web 1.0 os usuários simplesmente consumiam o conteúdo, mas a natureza da Web 2.0 supõe que os 
usuários têm mais participação na produção do conteúdo.

Essas novas ferramentas sociais se consolidaram como alternativas aos meios de comunicação tradicionais (TV, rádio, revistas, jornais, etc.) e seu público, e vêm oferecendo a possibilidade de dar um toque mais humano a essas mídias tradicionais. Neste cenário de mudanças, os bibliotecários passaram a reconhecer o universo 2.0 como suporte para auxiliar as Bibliotecas Universitárias (BUs) na aproximação com sua comunidade. Sobre a adoção de recursos da Web $2.0 \mathrm{em}$ bibliotecas acadêmicas, Brito e Silva (2010, p 32) afirmam que:

[...] as ferramentas participativas da Web 2.0 são uma oportunidade para a missão educativa da biblioteca, que estimulam leituras diversas, investigação documental, escrita e novas formas de comunicação, participação e criação coletiva de conhecimento, além da missão especial das bibliotecas universitárias, que é o ensino, a pesquisa e a extensão. Usá-las, faz com que seja proporcionado à comunidade usuária um ambiente mais agradável e de agregação de valor ao espaço virtual [e físico] da biblioteca (grifo nosso).

Diante das atuais formas de comunicação de massa, proporcionada pelas ferramentas 2.0, um novo cenário se desenha também para as BUs, que para continuarem sendo úteis à pesquisa e à produção de conhecimento no ambiente universitário devem reorganizar seus serviços para serem mais ativas no apoio aos usuários/clientes. Com isso, se reforça nos profissionais da informação a crença de que o entendimento das necessidades reais dos usuários é elemento essencial para obter qualidade em um serviço de informação, pois somente monitorando, analisando e avaliando suas atividades é que a biblioteca poderá obter um bom desempenho nos seus serviços (SHAUGHNESSY, 1987 apud VERGUEIRO; CARVALHO, 2001).

Considerando que os bibliotecários devam explorar a estatística, pois a interpretação de dados estatísticos fornece recursos importantes para melhorar serviços, produtos e planejar ações (MELO, 2004) e que esses estudos passaram a ser realizados por esses profissionais para assegurar que as bibliotecas ofereçam precisamente o que seus usuários necessitam (MACIEL, 1995), o presente trabalho mapeou e analisou as características das mídias sociais no contexto das bibliotecas universitárias públicas brasileiras para fornecer orientações para o uso dessas ferramentas no cenário biblioteconômico e apresentar sugestões para medir o uso e a eficácia da comunicação nessas mídias por meio de um Manual Básico de Uso de Mídias Sociais. Almeja-se que esta pesquisa traga um panorama da utilização das mídias sociais, por instituições públicas, para profissionais da informação que procurem conhecimento sobre essa temática dentro do serviço de bibliotecas acadêmicas.

Do empenho em melhorar o relacionamento da biblioteca com os usuários e ampliar a visibilidade dos produtos e serviços oferecidos pela mesma, surgiu por parte da autora deste trabalho - que atua há mais de 10 anos como bibliotecária de referência na Biblioteca do Instituto de Pesquisa e Planejamento Urbano e Regional (IPPUR) da Universidade Federal do Rio de Janeiro (UFRJ) - o interesse de conhecer melhor o universo das mídias sociais. Logo nos primeiros contatos com a temática foi percebido que essas mídias poderiam ser grandes aliadas no esforço de estreitar os laços da biblioteca com os usuários.

Desta forma, gradativamente no exercício diário da profissão, a autora foi implantando ações no mundo das mídias sociais, através da criação de serviços e produtos online hospedados em ambientes 2.0. E paulatinamente, para a autora, os meios de comunicação digital foram se consolidando como uma excelente vitrine para a exposição dos produtos e serviços de biblioteca e um ótimo instrumento para 
levar ao usuário/cliente toda e qualquer informação que se faça necessária para a geração de conhecimento acadêmico. As ações desenvolvidas no cenário 2.0 suscitaram convites para relatar, em palestras, para bibliotecários de universidades públicas, experiências sobre o uso dessas mídias.

Nos encontros com outros profissionais percebe-se que estes estão bem cientes sobre a necessidade das bibliotecas acadêmicas estarem presentes também no ambiente virtual e que isso já não é mais ponto de dúvidas. No entanto, os encontros evidenciaram certas indagações, por parte desses profissionais, sobre propósito de uso das mídias sociais em BUs. Da tentativa de satisfazer essas indagações nasce a motivação deste estudo que se justifica em primeiro lugar, por permitir uma oportunidade de estudar um fenômeno novo e crescente e também por contribuir para um melhor entendimento do uso dessas ferramentas.

A trajetória narrada na seção anterior do trabalho nos possibilitou perceber que muitas Bibliotecas Universitárias (BUs) desbravaram o cenário 2.0 e cumpriram a primeira fase do processo - a inserção das mídias sociais na rotina de trabalho das bibliotecas acadêmicas - mas o grau de compreensão das mídias sociais para uso pelos bibliotecários ainda é pouco claro. Isso porque, poucas BUs passaram para a segunda fase - a avaliação do uso das mídias sociais no ambiente biblioteconômico. Desta forma, é natural que profissionais com mais experiência, no uso das mídias sociais comecem a desenvolver processos que permitam ver o que está sendo feito nas bibliotecas acadêmicas para compreender melhor a aplicação desses recursos tecnológicos.

$\mathrm{O}$ presente estudo objetiva reunir informações sobre adoção das mídias sociais pelas bibliotecas acadêmicas do Sistema de Bibliotecas (SiBI) da Universidade Federal do Rio de Janeiro (UFRJ) através da percepção dos bibliotecários universitários e dos usuários/clientes das bibliotecas da universidade para oferecer insumos aos bibliotecários acadêmicos sobre as melhores práticas na adoção e avaliação das mídias sociais como um serviço e construir um Manual Básico de Uso de Mídias Sociais com instruções para uso e monitoramento das mídias sociais em bibliotecas acadêmicas.

\section{METODOLOGIA}

Neste estudo, utilizaremos duas etapas para coleta de dados: a primeira etapa uma pesquisa exploratória será realizada através de levantamento de dados na Internet. Logo após esta fase iniciá-se a segunda etapa - Pesquisa descritiva: aplicação de questionário a uma amostra de usuários/clientes da instituição e também a uma amostra de bibliotecários para contextualizar o uso das mídias sociais, e posterior análise estatística. Definimos como campo de análise o universo das bibliotecas do Sistema de Bibliotecas (SiBI) da Universidade Federal do Rio de Janeiro (UFRJ) situadas no município do Rio de Janeiro.

$\mathrm{Na}$ escolha da instituição para amostragem, houve uma motivação de conveniência pautada em 2 (dois) fatores principais: proximidade geográfica - a autora desta pesquisa atua como bibliotecária há mais de dez anos nessa instituição de ensino - e valor institucional - a instituição de ensino superior pública selecionada é reconhecida como a primeira instituição oficial de ensino superior do Brasil e serve como modelo para as demais instituições acadêmicas do país. Outro ponto relevante da escolha se refere ao total de bibliotecas do Sistema de Bibliotecas da UFRJ: 44 (quarenta e quatro) bibliotecas, um número expressivo se considerarmos que existem 170 (cento e setenta) bibliotecas universitárias públicas federais acadêmicas localizadas na região sudeste 
do Brasil (CALIL JUNIOR, 2013, p. 1063).

As bibliotecas da UFRJ representam $26 \%$ das bibliotecas públicas federais acadêmicas situadas na região sudeste do nosso país. Desta forma, essa pesquisa verificará como os bibliotecários e os usuários/clientes do Sistema de Bibliotecas (SiBI) da Universidade Federal do Rio de Janeiro (UFRJ) vêem a presença de suas bibliotecas nas mídias sociais. Espera-se, que este estudo, contribua para delineamento de novas pesquisas sobre o assunto, além de servir como referência para bibliotecários que desejem ampliar suas atuações no serviço público e no âmbito das Bibliotecas Universitárias.

A Universidade Federal do Rio de Janeiro (UFRJ) é constituída por 50 unidades acadêmicas, mais de 900 laboratórios e 44 bibliotecas no Sistema de Bibliotecas da Universidade Federal do Rio de Janeiro (SiBI/UFRJ), que teve início em 1983 com a função de organizar a aquisição de periódicos estrangeiros para a UFRJ e há 26 anos vem atuando para integração das bibliotecas da UFRJ às políticas acadêmicas e administrativas da instituição. De forma geral, é finalidade do $\mathrm{SiBI} / \mathrm{UFRJ}$ implementar políticas: de planejamento, de fomento à pesquisa, de gerenciamento de tecnologias, de desenvolvimento de acervos e de serviços de informação (UNIVERSIDADE FEDERAL DO RIO DE JANEIRO, 2014b). O quadro 1 a seguir mostra alguns dados, indicadores e uma descrição sucinta do universo da pesquisa.

Quadro 1: Caracterização da Coordenadoria do Sistema de Informação (SIBI) da Universidade Federal do Rio de Janeiro (UFRJ)

\begin{tabular}{|c|c|}
\hline COORDENAÇÃ̃O GERAL & SISTEMA DE BIBLIOTECAS E INFORMAÇÃ̃O (SIBI) \\
\hline ANO DE CRIAÇÃO & 1983 \\
\hline TOTAL DE BIBLIOTECAS & 44 \\
\hline $\begin{array}{l}\text { ACERVO (livros, monografias, materiais } \\
\text { especiais, coleções especiais, teses e } \\
\text { dissertações, obras raras e antigas, trabalhos de } \\
\text { conclusão de curso, objetos tridimensionais e } \\
\text { periódicos). }\end{array}$ & $\begin{array}{l}\text { Ano } 2014 \\
\text { Total: } 1.136 .146\end{array}$ \\
\hline CIRCULAÇÃO DO ACERVO & $\begin{array}{l}\text { Ano } 2014 \\
\text { Total de empréstimos: } 123.743 \quad \text { Total de consultas: } 126.805\end{array}$ \\
\hline CATÁLOGO COLETIVO & $\begin{array}{l}\text { Software Aleph } \\
\text { Base de dados: Minerva http://www.minerva.ufrj.br }\end{array}$ \\
\hline URL & http://www.sibi.ufrj.br \\
\hline USUÁRIOS INSCRITOS & $\begin{array}{l}\text { Ano } 2014 \\
39.360\end{array}$ \\
\hline $\begin{array}{l}\text { FLUXO DE USUÁRIOS (consulta, estudo, } \\
\text { convivência). }\end{array}$ & $\begin{array}{l}\text { Ano } 2014 \\
738.083\end{array}$ \\
\hline OBJETIVO & $\begin{array}{l}>\text { integrar suas bibliotecas à política educacional e administrativa da } \\
\text { Universidade; } \\
>\text { dar suporte aos programas de ensino, pesquisa e extensão da Universidade; } \\
\text { estimular a produção técnico-científica, literária e artística na Universidade; } \\
>\text { desenvolver serviços e produtos de informação que atendam as exigências de } \\
\text { relevância e rapidez. }\end{array}$ \\
\hline FINALIDADE & $\begin{array}{l}\text { Coordenar ações que visem integrar as bibliotecas à realidade educacional e } \\
\text { administrativa da universidade. }\end{array}$ \\
\hline
\end{tabular}

Fonte: Site do Sistema de Bibliotecas e Informação (SiBI) da UFRJ.

\section{MATERIAIS E MÉTODOS}

Conforme Cervo, Bervian e Silva (2007) a pesquisa exploratória é o passo inicial do processo de investigação e auxilia na formulação de hipóteses para estudos posteriores. Este tipo de estudo se justifica quando o tema foi pouco estudado:

[...] realizada em área na qual há pouco conhecimento acumulado e sistematizado. Portanto, apresenta uma natureza de sondagem. É o estudo preliminar, com a ajuda de bibliografia básica, para esclarecer dúvidas nos primeiros passos da pesquisa. 
Estas pesquisas têm como objetivo proporcionar maior familiaridade com o problema, com o propósito de torná-lo mais explícito. Apresentam planejamento flexível, de modo que possibilite a consideração dos mais variados aspectos relativos ao fato estudado (UNIVERSIDADE ESTÁCIO DE SÁ, 2008, p.100-101).

O melhor método para ilustrar a forma como as mídias sociais estão sendo utilizadas pelas bibliotecas públicas acadêmicas brasileiras é através da observação de exemplos concretos. Desta forma, selecionamos as bibliotecas públicas do Sistema de Bibliotecas e Informação (SiBI) da Universidade Federal do Rio de Janeiro (UFRJ) como campo para nossa análise e realizamos uma análise inicial (preliminar) no Site do Sistema de Bibliotecas do SiBI para identificar as bibliotecas do sistema que fariam parte da amostra, para a partir daí, reunir as informações necessárias.

A amostra foi construída por 31 (trinta e uma) bibliotecas, cabendo ressaltar que não consideramos para efeitos do estudo exploratório as bibliotecas da universidade situadas fora do município do Rio de Janeiro e as bibliotecas com públicos especiais como: as bibliotecas de obras raras e antigas, a biblioteca do Colégio de Aplicação, os postos de serviço de informação, a biblioteca do Projeto Xistoquímica, as bibliotecas do Forum de Ciência e Cultura, e a biblioteca da Central de Memória Acadêmica. Após o desenho da amostra realizamos buscas na ferramenta Google com os seguintes objetivos:

a) Identificar as bibliotecas do Sistema de Bibliotecas (SiBI) da Universidade Federal do Rio de Janeiro (UFRJ) que estão presentes na $W e b$;

b) Fornecer uma visão geral das práticas relativas à utilização das mídias sociais pelas bibliotecas acadêmicas.
A pesquisa descritiva de acordo com Gil (2009, p. 42) "têm como objetivo

primordial a descrição das características de determinada população ou fenômeno ou, então, o estabelecimento de relações entre variáveis". A finalidade do estudo descritivo é retratar um perfil sobre: pessoas, eventos ou situações. Este tipo de pesquisa se justifica quando:

[...] descreve idéias, coisas, processos, com a intenção de compreender o objeto da investigação. Expõe características de determinada população ou de determinado fenômeno. Não têm compromisso de explicar os fenômenos que descreve, embora sirva de base para tal explicação. Dentre as pesquisas descritivas são comuns as que têm por objetivo estudar as características de um grupo: sua distribuição por idade, sexo, procedência, nível de escolaridade, estado de saúde física e mental, etc. (UNIVERSIDADE ESTÁCIO DE SÁ, 2008, p. 101).

Como técnica de pesquisa será utilizada o levantamento de dados através da aplicação de questionário. Marconi e Lakatos (2010) conceituam essa técnica como um instrumento de coleta de dados, constituído por uma série ordenada de perguntas que devem ser respondidas sem a presença do entrevistador. $\mathrm{O}$ presente estudo vai preocupar-se com 0 fornecimento de estatísticas descritivas sobre a aplicação das mídias sociais em bibliotecas acadêmicas brasileiras. $\mathrm{O}$ desenho de pesquisa buscou elaborar um estudo descritivo a dois grupos de atores do cenário biblioteconômico: usuários/clientes e bibliotecários, para análise quantitativa de frequências. Foram aplicados dois tipos de instrumentos para as 2 (duas) populações: População (A) formada pelos usuários/clientes do Sistema de Bibliotecas e Informação (SiBI) da Universidade Federal do Rio de Janeiro (UFRJ) e População (B) formada por bibliotecários das bibliotecas do Sistema de Bibliotecas e Informação (SiBI) da Universidade Federal do Rio de Janeiro (UFRJ). 
Se considerarmos os bibliotecários como gestores da informação e as bibliotecas como organização de serviços é fundamental que estas se apóiem em dados estatísticos para melhorar seus serviços, produtos, planejar suas ações e compreender as necessidades sua clientela (MELO, 2004), pois eles fornecem recursos importantes para o gestor da biblioteca avaliar e planejar os serviços (MACIEL, 1995). É necessário ressaltar que escolhemos o ambiente virtual como meio ideal de coletar os dados para a pesquisa, visto que este universo é a essência dos objetivos deste estudo.

As bibliotecas universitárias são instituições de caráter público, ou seja, estão abertas para a sociedade em geral que tem como missão fornecer suporte informacional aos programas de ensino, de pesquisa e de extensão da universidade. A escolha das duas populações nasce do pensamento de Almeida (2000, p. 13) que afirma que é preciso haver uma atitude permanente de indagação e análise, por parte do bibliotecário, em relação à situação real da unidade de informação para estimular a criatividade, favorecer a mudança, evitar a acomodação da equipe e garantir a eficácia das Bibliotecas Universitárias.

A escolha do estudo da Populaçãoalvo (A) se deu pela consonância ao pensamento expresso por Almeida (2000) de que estudos relativos ao público das unidades de informação Estudos de Usuários - são essenciais para medir a qualidade do serviço (ou atividade), ou o grau de satisfação desses usuários com os serviços e produtos que lhes são oferecidos. Portanto:

[...] o estudo de usuários permite que os bibliotecários conheçam tanto as necessidades de informação dos usuários quanto a satisfação desses com relação aos serviços e produtos fornecidos pela unidade de informação [...] (SEPÚLVEDA; ARAÚJO 2012, p. 271).

Desta forma, esta pesquisa foi aplicada à comunidade acadêmica usuária do
Sistema de Bibliotecas da UFRJ - alunos, professores, pesquisadores, técnicos administrativos em educação e a comunidade em geral - com intuito de identificar os interesses e opiniões dos usuários/clientes objetivando avaliar o uso das mídias sociais sob o ponto de vista dos usuários das bibliotecas.

A escolha do estudo da segunda amostra - População-alvo (B) - se deu pela afirmação de Sepúlveda e Araújo (2012, p. 278) "[...]que os bibliotecários conhecem e dominam todas as questões referentes ao universo das bibliotecas [...]". Na prática, esse profissional é um permanente sensor das necessidades informacionais em uma instituição (ALMEIDA, 2000, p. 13). Assim, esta pesquisa descritiva ocupou-se de investigar o uso das ferramentas de redes sociais em bibliotecas universitárias, examinando a extensão de seu uso sobre as percepções dos bibliotecários do Sistema de Bibliotecas da UFRJ.

No que diz respeito à organização do questionário, este foi constituído por 10 (dez) perguntas, sendo 9 (nove) perguntas objetivas e 1 (uma) perguntas aberta) Apêndice A - baseadas na revisão bibliográfica e divididas em 5 (cinco) grupos de objetivos (Quadro 2). As questões de pesquisa norteadoras deste estudo foram Seção (A) usada para descobrir os atributos individuais do entrevistado (idade, escolaridade ou atividade exercida e região geográfica). Seguida da $\operatorname{Seção~}(B)$ que objetivou medir a tecnologia (forma de acesso) dos usuários das mídias sociais, pela Seção (C) projetada para coletar informações sobre as mídias sociais mais usadas. Já a Seção (D) coletou o grau de satisfação e atualização das mídias sociais dentro das Bibliotecas da UFRJ. E a última seção, (E) contou com uma questão aberta onde se coletaram informações complementares: elogios, críticas, comentários e sugestões da população estudada. 
Quadro 2: Estruturação do questionário da população (A)

\begin{tabular}{|c|c|c|}
\hline $\begin{array}{c}\text { ETAPAS } \\
\text { DO } \\
\text { QUESTIONÁRIO }\end{array}$ & FINALIADE & ESTRUTURAÇÃO \\
\hline Seção (A) & $\begin{array}{l}\text { Identificação das características gerais sócio- } \\
\text { demográficas (idade, escolaridade e/ou atividade } \\
\text { exercida e região geográfica). }\end{array}$ & $\begin{array}{l}3 \text { (três) questões (1-3) para descobrir os atributos } \\
\text { individuais (idade, escolaridade (ou atividade exercida) } \\
\text { e região geográfica) do entrevistado. }\end{array}$ \\
\hline Seção (B) & $\begin{array}{l}\text { Identificação da forma de acesso e identificação } \\
\text { das mídias sociais mais usadas. }\end{array}$ & $\begin{array}{l}2 \text { (duas) questões (4-5) para medir a tecnologia (forma } \\
\text { de acesso) e identificação do tipo de mídia social mais } \\
\text { usada pelo entrevistado. }\end{array}$ \\
\hline Seção (C) & $\begin{array}{l}\text { Identificação da relevância das informações } \\
\text { disponibilizadas nas mídias sociais das } \\
\text { bibliotecas da UFRJ e a percepção dos usuários } \\
\text { sobre a utilidade da interação entre as } \\
\text { Bibliotecas da UFRJ e seus usuários nas mídias } \\
\text { sociais. }\end{array}$ & $\begin{array}{l}2 \text { (duas) questões (6-7) que buscam revelar o ponto } \\
\text { vista do entrevistado sob o grau de importância das } \\
\text { informações disponibilizadas nas mídias e sua } \\
\text { percepção sobre a utilidade interação dos usuários com } \\
\text { as Bibliotecas da UFRJ nas mídias sociais. }\end{array}$ \\
\hline Seção (D) & $\begin{array}{l}\text { Identificação do grau de satisfação e atualização } \\
\text { das mídias sociais dentro das Bibliotecas da } \\
\text { UFRJ. }\end{array}$ & $\begin{array}{l}2 \text { (duas) questões (8-9) que revelarão o grau de: } \\
\text { satisfação e atualização das mídias sociais dentro das } \\
\text { Bibliotecas da UFRJ. }\end{array}$ \\
\hline Seção (E) & Identificação das informações complementares. & $\begin{array}{l}1 \text { (uma) questão (10) aberta que coletará informações } \\
\text { complementares que apurará elogios, comentários, } \\
\text { críticas e sugestões da população estudada. }\end{array}$ \\
\hline
\end{tabular}

Fonte: Próprio autor.

O questionário aplicado a população (B) - Apêndice A - foi desenhado com o intuito de apurar o posicionamento dos bibliotecários das Bibliotecas Universitárias (BU) com relação às mídias sociais. Composto por 10 (dez) perguntas objetivas e 3 (três) perguntas abertas (Quadro 3) nosso instrumento foi dividido em 2 (duas) partes principais: a primeira delas solicitou informações sobre a idade dos participantes. E por fim, na ultima etapa, 9 (nove) questões objetivas e três questões abertas foram apresentadas com o intuito de avaliar a percepção destes profissionais em relação as mídias sociais. Nosso objetivo era contar com a experiência prévia dos respondentes no uso das mídias sociais no nível profissional e pessoal.

Quadro 3: Estruturação do questionário da população (B)

\begin{tabular}{|c|c|}
\hline ESTRUTURAÇÃO & FINALIDADE \\
\hline 1 (uma) questão objetiva. & $\begin{array}{l}\begin{array}{l}\text { Identificação das características gerais sócio-demográficas } \\
\text { (idade). }\end{array} \\
\text { (ide }\end{array}$ \\
\hline  & $\begin{array}{l}\text { Que revelarão o ponto vista dos bibliotecários sob a utilização das } \\
\text { mídias sociais nas Bibliotecas da UFRJ. }\end{array}$ \\
\hline
\end{tabular}

Fonte: Próprio autor.

A coleta dos dados para as 2 (duas) populações A e B ocorreu durante os meses de novembro e dezembro de 2015. O modelo de questionário eletrônico foi escolhido, como método de coleta de dados, porque este tipo de questionário garante o envolvimento dos respondentes e é habitualmente usado em pesquisas de opinião. Assim sendo, escolhemos o aplicativo Google Forms (formulários Google) para elaborar os questionários. Esta ferramenta conta com uma infraestrutura que permite desde a elaboração do questionário até a tabulação dos resultados de forma automática incluindo a construção de gráficos.

Os entrevistados da População-alvo (A) foram informados sobre o estudo, através de uma postagem explicativa na página do Facebook da Biblioteca do IPPUR/UFRJ. Na postagem havia um link (endereço eletrônico) para a página que hospedava o formulário eletrônico. Já os respondentes da População-alvo (B) 
foram informados sobre o estudo, por meio de um e-mail enviado a lista de discussão institucional SiBiListas - uma lista de e-mails, por meio da qual o Sistema de Bibliotecas e Informação (SiBI) da Universidade Federal do Rio de Janeiro (UFRJ) envia comunicados aos bibliotecários - no corpo do e-mail havia um link para a página que hospedava o questionário eletrônico da pesquisa.

\section{DISCUSSÃO DOS RESULTADOS}

Criar uma marca, ou seja, uma identidade institucional na Internet não é novidade. Esse trabalho já está em andamento em órgãos públicos $\mathrm{e}$ privados, mas muito ainda se discute sobre os instrumentos para que nossas bibliotecas se façam presente no mundo virtual (ciberespaço). Nossa pesquisa ocupou-se em entender as atividades virtuais das bibliotecas acadêmicas para pensar em processos que possibilitem otimizar a participação das mesmas no (ciberespaço). Para cumprir o propósito, realizamos pesquisas com o intuito de apurar $\quad 0 \quad$ comportamento das Bibliotecas universitárias (BUs) públicas, seus bibliotecários universitários e usuários com relação ao uso das mídias sociais.

A pesquisa da População-alvo (A) foi aplicada à comunidade acadêmica usuária do Sistema de Bibliotecas da UFRJ alunos, professores, pesquisadores, técnicos administrativos em educação e a comunidade em geral, que uma vez informada sobre o estudo, responderam espontaneamente às questões. $\mathrm{E}$ assim, o desenho amostral da População (A) foi constituído por 108 entrevistados que responderam espontaneamente as questões formuladas. Já a pesquisa da População (B) foi aplicada aos 219 bibliotecários - segundo os dados da Coordenação do SiBI/UFRJ -Informado sobre o estudo, 44 bibliotecários responderam espontaneamente às questões, resultando em uma taxa de resposta (percentual de pessoas que responderam o questionário) de $20 \%$.

$O$ percentual baixo pode ser justificado por possíveis falhas no envio das mensagens e mudança no endereço eletrônico dos entrevistados. Os grupos entrevistados se mostraram bem conscientes sobre o tema e contribuíram para esta dissertação com idéias, opiniões e observações relevantes sobre o uso da comunicação social. Nosso olhar na esfera digital forneceu alguns resultados muito interessantes sobre a adoção das sociais mídias nas BUs e como usuários e bibliotecários entendem esse trabalho. A presença das unidades de informação na Web possibilita que estas organizações divulguem seus serviços de informação e favorecem que seus usuários/clientes obtenham informações sem ter, necessariamente, comparecer às instalações físicas da biblioteca. Nosso estudo revelou que $87 \%$ das bibliotecas da UFRJ marcam presença nas homepage (sites) institucionais dos centros (institutos, escolas, etc.).

Neste contexto, chamamos a atenção para o fato que uma página própria exclusiva independente dos portais institucionais, ambientada nas ferramentas 2.0 poderia não só aumentar a atratividade das unidades de informação, como também favorecer ações capazes de ampliar o número das informações disponibilizadas pelas bibliotecas universitárias além de contribuir ainda para ampliar o uso efetivo dos recursos disponíveis por estas instituições. As homepage institucionais são importantes plataformas para promoção do uso efetivo dos recursos disponíveis nas unidades de informação. Elas dão acesso prévio aos usuários não só as informações essenciais como o acervo das bibliotecas universitárias, mas também facilitam o desenvolvimento ações voltadas para programas de educação de usuários, além de contribuir para dar visibilidade e favorecer o uso efetivo dos recursos 
institucionais disponíveis a exemplo os produtos e/ou serviços biblioteconômicos.

Tendo em vista que o objetivo de uma biblioteca acadêmica é proporcionar ao usuário/cliente acesso à informação, é primordial importância dar visibilidade aos seus produtos e/ou serviços. Contemplando os dados estatísticos podemos deduzir que as mídias sociais estão aprovadas para utilização e incorporadas nos processos de comunicação das bibliotecas universitárias. Os resultados demonstram que estas organizações estão com mais de 3 (três) anos de utilização da ferramenta social, isso prova uma abertura por parte das bibliotecas acadêmicas no sentido de implementar ações no universo 2.0. Os ambientes sociais podem ser usados pelas bibliotecas acadêmicas como um meio para transmitir informações e se conectar com os usuários/clientes.

Nestas plataformas, as bibliotecas podem socializar seus serviços fora do seu espaço físico e se promover de uma maneira eficaz. Essas mídias também são uma ótima alternativa para suprir a falta de homepage (sites) institucionais das unidades de informação, pois facilita a inclusão digital/virtual destas instituições no universo Web. Com o beneficio de que para usá-las não é necessário possuir nenhuma habilidade de Web design. A apuração dos dados constata a liderança clara do Facebook, que tem uma penetração superior às outras ferramentas sociais e se consolida, nas bibliotecas acadêmicas, como peça central em termos de ferramenta de comunicação digital e difusão de conteúdos. Um ponto central para ações desenvolvidas no cenário 2.0, mas pelo estudo emergem também outras ferramentas sociais: a ferramenta de compartilhamento de vídeos Youtube e o serviço de armazenamento em nuvem Google Drive. Nesse contexto, aconselha-se a intensificação de ações nestes canais que parecem ser bem aceitas pela comunidade universitária.

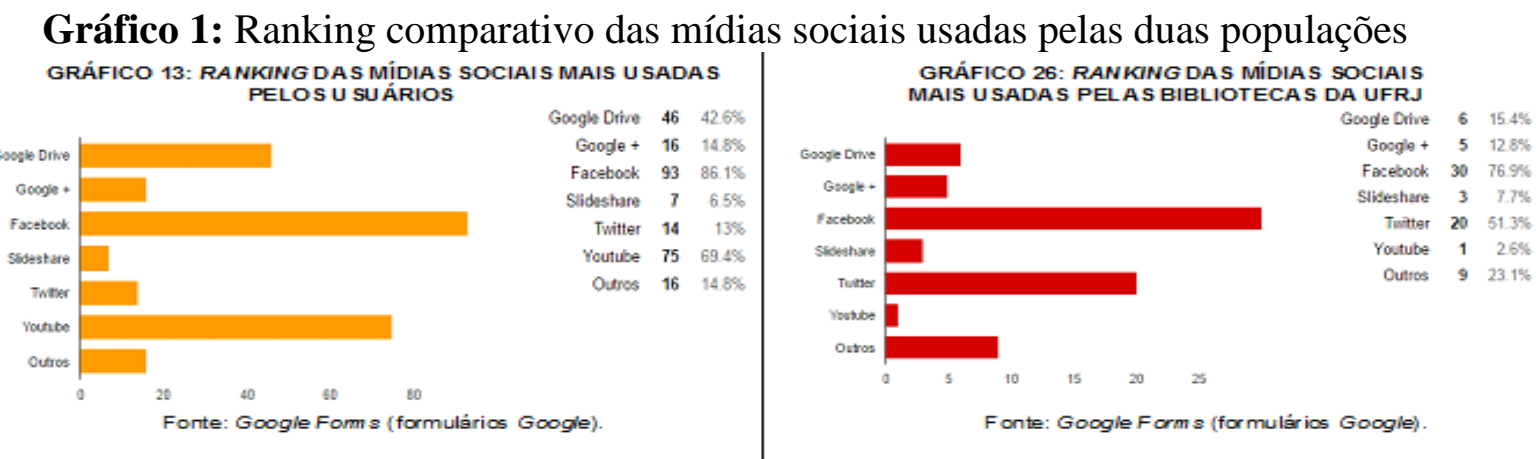

Fonte: Google Forms (formulários Google).

Sobre o perfil dos usuários respondentes, os resultados provam uma descoberta confirmada pela tendência, visto que a esmagadora maioria dos questionários respondidos adveio de pessoas que possui vínculo com a Universidade $(81,5 \%)$. Os estudantes universitários representam o maior grupo de usuários do Sistema de Bibliotecas da UFRJ (49,1\%). Surpreendentemente a segundo grupo mais representativo foi $o$ grupo dos "sem vínculo com a UFRJ" $(18,5 \%)$ em contraste, com os outros grupos da população acadêmica: servidores da UFRJ $(16,7 \%)$ da Universidade, professores e/ou pesquisadores da UFRJ $(11,1 \%)$ e outras formas de ligação com a UFRJ 4,6\%.

Isso demonstra a amplitude do alcance que a inserção das bibliotecas acadêmicas no universo das mídias sociais, pois permite que estas organizações atuem 
também como centros de ação cultural e educacional permanentes tornando-as fonte de informação para populações que estão à margem do cenário universitário. E reforça a ideia que as mídias sociais proporcionam acesso ilimitado, e tem potencial para aumentar o nível de popularidade, visibilidade das unidades de informação com aporte para quebrar a barreira geográfica e ultrapassar os limites impostos pela distância.

Seguindo essa linha de raciocínio é importante que os bibliotecários conheçam as mídias mais usadas por seus usuários para tirar o máximo proveito deste veículo, visto que a comunidade universitária gasta horas por dia nas mídias sociais, lendo e postando informações. Com a análise técnica percebemos que as tecnologias de Internet aliada às tecnologias de telefonia celular aceleraram a criação de novas formas de interações humanas, transformaram a comunicação da sociedade contemporânea e modificaram a sociedade nas formas de ser, conhecer, comunicar e produzir.

Com relação a forma de acesso à $W e b$, os usuários entrevistados disseram que o principal local de conexão para as mídias sociais é o expoente incontestável da Internet móvel, o Smartphone. Este dispositivo atualmente já compete em pé de igualdade com o computador portátil (Notebooks - 75,9\%) e com o PC/Desktops (computador de mesa 63\%). Desta forma, o acesso a Web é mais frequente em terminais móveis. Essa constatação permite afirmar que é essencial que todas as bibliotecas e em especial, as acadêmicas atentem para essa demanda. Os dados levantados no estudo identificaram uma demanda dos bibliotecários respondentes.

Esses profissionais sinalizaram dificuldades com relação a medição do trabalho das bibliotecas nos meios de comunicação digital e declaram não estar habilitados para avaliar a presença de suas bibliotecas nas mídias sociais. É conveniente ressaltar que é essencial medir as ações desenvolvidas no cenário social para se manter a par do que está acontecendo neste ambiente e saber se os resultados estão sendo alcançados. Assim, na seção "Apêndices" deste trabalho propõe-se uma metodologia simples para nortear os profissionais da informação como medir o desempenho de suas ações nos meios de comunicação social, a fim de valorizar o esforço e resultados. Em conclusão pode-se dizer que, no contexto das bibliotecas acadêmicas públicas, o meio de comunicação digital agora é uma característica permanente e em constante estado de desenvolvimento tal qual a essência das bibliotecas, tão bem lembrada por Targino (2010) quando chama a atenção para a quinta lei de Ranganathan: "A biblioteca é um organismo em crescimento”.

\section{CONSIDERAÇÕES FINAIS E PERSPECTIVAS FUTURAS}

Nossa meta foi estudar as mídias sociais, das bibliotecas acadêmicas da UFRJ, para fornecer resultados sobre a forma de como as bibliotecas acadêmicas e seus clientes usam essas redes. Essa motivação nasceu sob a crença de que, tais elementos, trazem benefícios para os esforços de marketing destas organizações. Benefícios estes, óbvios para as organizações comerciais e ainda nebulosos para as bibliotecas. Habitualmente relacionamentos virtuais na Internet são reflexos das relações em no mundo físico. Assim, possuir um canal ativo com usuários na Web pode ajudar as bibliotecas a divulgarem informações sobre o acervo, ferramentas de busca, produtos e serviços, etc.

Deve-se se levar em conta também que usuários mais ativos da Web, ou seja, que os seguidores ativos nas mídias sociais, podem ajudar o profissional da informação a divulgar os recursos informacionais da biblioteca para toda a comunidade acadêmica e também captar 
usuários possíveis que podem pertencer a outras instituições públicas e privadas. Em um mercado cada vez mais concorrido, oferecer melhores produtos e serviços já não é o suficiente, isto porque não há produto ou serviço bom o bastante. Uma maneira de competir no mercado é garantir a satisfação dos clientes. Sendo assim, ouvir as opiniões dos usuários para melhorar o desempenho e fidelizar os clientes são itens essenciais para sobrevivência das instituições e/ou organizações (FIDELIZAÇÃO..., 2015).

Antes da Internet as bibliotecas, nem sempre tinham essa atitude. Talvez porque não fosse necessário uma vez que os recursos disponíveis, nestas organizações, eram únicos e não havia outro lugar para encontrá-los. Mas a internet mudou tudo isso e agora as bibliotecas competem também com um ambiente de fontes de informação diversificada e abundante disponível na $W e b$ e para defender sua própria relevância precisam operar também neste ambiente concorrente. Recentemente o Instituto Pró-Livro, revelou em uma pesquisa do que: $66 \%$ dos brasileiros não frequentam bibliotecas, e outros $14 \%$ visitam raramente o local, segundo Dalgiza Oliveira - professora de biblioteconomia da Universidade Federal de Minas Gerais (UFMG) - uma das explicações para a impopularidade das bibliotecas é a falta de visibilidade, onde a própria comunidade do entorno, dessas organizações, não conhece as possibilidades que o espaço oferece (QUESADA, 2016).

O coordenador do Sistema Municipal de Bibliotecas de São Paulo, Waltemir Nalles, acredita que mudanças, nesse quadro, devem ser realizadas pelos próprios bibliotecários. Para Nalles, esses profissionais são responsáveis diretos e devem desenvolver ações que façam das bibliotecas uma extensão das comunidades onde estão inseridas (QUESADA, 2016). Desta forma, criar mecanismos para desenvolver relações com os usuários, ir ao seu encontro, ouvir suas demandas, satisfazer suas expectativas, é agora essencial para a sobrevivência destas organizações. Os dados coletados no estudo indicaram que os dois grupos pesquisados apresentam alta frequência de acesso às mídias sociais.

Reconhece-se em todas as fases da pesquisa que o Facebook é o canal mais popular de mídia social nas bibliotecas acadêmicas e que este não deve ser visto somente como um canal de comunicação, mas sim também, como um meio útil para desenvolver ações com alunos, professores e funcionários, pois permite a integração de diversos recursos e fornece alternativas de acesso a diferentes serviços que podem gerar grandes oportunidades no ambiente universitário. $\mathrm{O}$ relacionamento dos indivíduos com as mídias sociais é um assunto relativamente recente e rico, mas que ainda carece de muitos estudos. Na literatura profissional encontram-se alguns estudos com os mais variados enfoques: padrões de comportamentos, opiniões dos bibliotecários relativas ao tema, além de análises sobre o desenvolvimento de uma mídia social especifica.

O presente trabalho espera ter contribuído com o debate acerca do tema. Prever o futuro da mídia social é uma tarefa muito difícil. $O$ futuro das bibliotecas acadêmicas, neste universo contínuo e onipresente, está aberto ao debate. Nessa perspectiva, ganha destaque a necessidade das bibliotecas acadêmicas serem mais estratégicas, para divulgar seus serviços e/ou produtos. E a mídia social oferece uma oportunidade para esta iniciativa. Contudo compreender as necessidades do público envolvido é tema chave para o sucesso das ações desenvolvidas no universo das tecnologias 2.0. Isso porque, se os bibliotecários universitários tiverem uma melhor compreensão do perfil e do comportamento dos usuários no cenário social podem planejar melhor suas 
atividades online e consequentemente destas

mídias atender melhor os usuários membros

\title{
THE PRESENCE OF THE UNIVERSITY LIBRARY IN SOCIAL MEDIA: A STUDY BASED ON THE UFRJ LIBRARY SYSTEM
}

\begin{abstract}
This study investigated the use of social media in thirty-one libraries of the Federal University of Rio de Janeiro to understand how to use these tools and weave guidelines for the proper use of monitoring tools in biblioteconomico scenario. The study was based on observation techniques and interviews to ascertain the perception of librarians and users in the use of media in the context of academic libraries. While the importance of communication channel that is recognized by both respondents as a means of promoting products and services, the results indicated that social media are not the dominant elements of the universe of academic libraries.
\end{abstract}

Keywords: Social media. Facebook. Twitter. University Library. Web 2.0. Metrics and Monitoring Social Media.

\section{REFERÊNCIAS}

ACCART, Jean-Philippe. Serviço de referência: do presencial ao virtual. Prefácio de Patrick Bazin. Tradução de Antônio Agenor Briquet de Lemos. Brasilia: Briguet de Lemos, 2012.

AGUIAR, Giseli Adornato de. Uso das ferramentas de redes sociais em bibliotecas universitárias: um estudo exploratório na UNESP, UNICAMP e USP.

2012. 184f. Dissertação (Mestrado em Ciência da Informação) - Escola de Comunicações e Artes, Universidade de São Paulo, São Paulo, 2012.

ALMEIDA, Maria Christina Barbosa de. Planejamento de bibliotecas e serviços de informação. Brasília: Briquet de Lemos/Livros, 2000. 112 p

ALVIM, Luísa. Impossível não estar no Facebook! O nascimento das bibliotecas portuguesas na rede social. Cadernos Bad, n. 1/2, 2011.

ANGLADA, Lluís. ¿Son las bibliotecas sostenibles en un mundo de información libre, digital y en red? El profesional de la información, v. 23, n. 6, p. 603-611, 2014. Disponível em:

http://recyt.fecyt.es/index.php/EPI/article/v iew/31974>. Acesso em: 2 fev. 2015.

ANJOS, Cláudia Regina dos et al. O Serviço de Referência da Biblioteca do Instituto de pesquisa e Planejamento Urbano e Regional IPPUR/UFRJ e seu Programa de Capacitação de Usuários. Biblionline, João Pessoa, v. 8, n. 1, p. 9096, 2013.

ANJOS, Cláudia Regina dos et al. Utilizando os recursos da Web 2.0 para inovar os serviços de biblioteca: um relato de experiência da Biblioteca do IPPUR/UFRJ. In: CONGRESSO BRASILEIRO DE BIBLIOTECONOMIA, 
DOCUMENTAÇÃO E CIÊNCIA DA INFORMAÇÃO, 25., 2013, Florianópolis. Anais. Florianópolis: FEBAB, 2013.

BARROS, Moreno. Altmetrics: métricas alternativas de impacto científico com base em redes sociais. Perspectivas em Ciência da Informação, v.20, n.2, p.19-37, abr./jun. 2015. < http://www.scielo.br/pdf/pci/v20n2/14139936-pci-20-02-00019.pdf > . Acesso em: 10 jul. 2016.

BARROS, Moreno Albuquerque de. Emergência e dinâmica informacional na blogosfera. Dissertação - Programa de Pós-graduação em Ciência da Informação. Mestrado em Ciência da Informação, Convênio Universidade Federal Fluminense - Instituto de Arte e Comunicação Social, Instituto Brasileiro de Informação em Ciência e Tecnologia. Niterói, Rio de Janeiro. 2009.

\section{BEAL, A. Gestão Estratégica da} informação: como transformar a informação e a tecnologia da informação em fatores de crescimento e de alto desempenho nas organizações. São Paulo: Atlas, 2004.

BRASIL. Secretaria de Comunicação Social da Presidência da República. Pesquisa brasileira de mídia 2015: hábitos de consumo de mídia pela população brasileira. Disponível em: < http://www.secom.gov.br/atuacao/pesquisa /lista-de-pesquisas-quantitativas-equalitativas - e - contratos-atuais/pesquisabrasileira-de-midia-pbm-2015.pdf $>$. Acesso em: 6 set. 2015.

BRITO, Jorgivania Lopes; SILVA, Patrícia Maria da. Ferramentas da web $2.0 \mathrm{em}$ bibliotecas universitárias: um estudo de caso. In: ENCONTRO NACIONAL DE ESTUDANTES DE BIBLIOTECONOMIA, DOCUMENTAÇÃO, GESTÃO E CIÊNCIA DA INFORMAÇÃO 33., 2010.
Paraíba. Anais. Paraíba: ENEBD, 2010.

Disponível em: <

http://periodicos.ufpb.br/ojs/index.php/bibl io/article/viewFile/9617/5232 > . Acesso em: 30 jan. 2015.

CALIL JUNIOR, Alberto. Mídias sociais nas bibliotecas universitárias brasileiras. Revista ACB: Biblioteconomia em Santa Catarina, v. 18, n. 2, p. 10531077, jul./dez. 2013. Disponível em: < http://www.brapci.inf.br/_repositorio/2014/ 05/pdf_303b667784_0024537.pdf>.

Acesso em: set. 2015.

CALIL JUNIOR, Alberto; CORRÊA, Elisa Cristina Delfini; SPUDEIT, Daniela. O uso das mídias sociais nas bibliotecas brasileiras: análise dos trabalhos apresentados no SNBU e CBBD. In: CONGRESSO BRASILEIRO DE BIBLIOTECONOMIA, DOCUMENTAÇÃO E CIÊNCIA DA INFORMAÇÃO-FEBAB. 2013 Anais. p. 5044-5059. Disponível em: < http://portal.febab.org.br/anais/article/view $/ 1634 / 1635$

>. Acesso em: set. 2015.

COMITÊ GESTOR DA INTERNET NO BRASIL. TIC Domicílios indica que $31 \%$ da população brasileira usa Internet pelo telefone celular. Disponível em: <http://www.cgi.br/noticia/ticdomicilios-indica-que-31-da-populacaobrasileira-usa-internet-pelo-telefonecelular/10044>. Acesso em: out. 2014.

DICAS para revistas científicas ganharem visibilidade no Facebook. Disponível em: $<$ https://blogdivulgaciencia.wordpress.com /2015/09/11/tutorial-facebook/ > . Acesso em: 15 jul. 2016.

FIDELIZAÇÃO de clientes: 5 dicas essenciais para encantar o comprador manter o cliente pode ser mais importante do que conquistar um novo. 26 jun. 2015. Revista Pequenas Empresas \& Grandes Negócios. Disponível em: 
http://revistapegn.globo.com/Dia-adia/noticia/2015/03/fidelizacao-de-clientes5-dicas-essenciais-para-encantar-ocomprador.html. Acesso em: 15 jul. 2016.

GIL, Antonio Carlos. Métodos e técnicas de pesquisa social. São Paulo: Atlas, 2009.

GONÇALVES, Marcio; NUNES, Alexandre. Contexto das Mídias Sociais em Alagoas: desafios para a (in) formação dos profissionais. Ciência da Informação em Revista, Maceió, v. 2, n. 1, p. 24-33, jan./abr. 2015. Disponível em: < http://www.seer.ufal.br/index.php/cir/articl e/view/1703>. Acesso em: 10 jul. 2016.

MACIEL, Alba Costa. Instrumentos para gerenciamento de bibliotecas. Niterói: EDUFF, 1995.

MARCONI, Mariana de Andrade; LAKATOS, Eva Maria. Fundamentos de metodologia científica. 7 ed. São Paulo: Atlas, 2010.

MARTINS, Wilson. Palavra escrita. São Paulo: Ática, 1996.

MELO, Luiza Baptista. Estatistica e avaliação da qualidade e do desempenho em bibliotecas e serviços de informação: investigações recentes e novos projetos, 2004. Disponivel em: < http://eprints.rclis.org/6478/ >. Acesso em: 5 jun. 2015.

MILANESI, Luiz. O que é biblioteca. 9. ed. São Paulo: Brasiliense, 1993. 107 p.

PEREIRA, Edinete Nascimento; CARVALHO, Andréa Vasconcelos. A Web 2.0 no Serviço de Referência: análise do uso nas bibliotecas das universidades federais do Nordeste brasileiro. Informação \& Informação, v. 17, n. 3, p. 102-124, 2012.
QUESADA, Beatriz. Desafios para tornar as bibliotecas públicas mais atraentes: além de problemas estruturais, imagem negativa do ambiente afasta o público. Revista Educação. Extras. Edição 230. Disponível em: <

http://revistaeducacao.com.br/textos/230/d esafios-para-tornar-as-bibliotecas-publicasmais-atraentes-371778-1.asp >. Acesso em: 15 jul. 2016.

SCHONS, Cláudio Henrique; RIBEIRO, Adriano Carlos; BATTISTI, Patrícia.

Educação a distância: Web 2.0 na construção do conhecimento coletivo. 2008. Disponível em: <

https://repositorio.ufsc.br/bitstream/handle/ 123456789/61430/243o_do_Conhecimento _Coletivo.pdf?sequence $=1>$. Acesso em: 14 nov. 2014.

SEPÚLVEDA, Maria Inês Moreira; ARAÚJO, Carlos Alberto Ávila.

Realização de estudos de usuários na prática profissional bibliotecária: estudo de caso do sistema de bibliotecas da UFMG,

Revista ACB: Biblioteconomia em Santa Catarina, Florianópolis, v.17, n.2, p.269287, jul./dez., 2012. Disponível em: < revista.acbsc.org.br/racb/article/download/ 842/pdf>. Acesso em: 14 nov. 2014.

TARGINO, Maria das Graças.

Ranganathan continua em cena. Ciência da Informação, Brasília, DF, v.39 n.1, p. Brasília, jan./apr. 2010. Disponível em:< http://www.scielo.br/scielo.php?script=sci arttext\&pid=S0100-19652010000100008 > . Acesso: 11 jul. 2016.

UNIVERSIDADE ESTÁCIO DE SÁ.

Núcleo de Qualificação e Apoio DidáticoPedagógico. Metodologia no ensino do direito. 2008. Disponível em: $<$ http://www.faeso.edu.br/downloads/Meto dologia\%20no\%20Ensino\%20do\%20Direit o.pdf >. Acesso em: set 2014.

UNIVERSIDADE FEDERAL DO RIO DE JANEIRO. Sistema de Bibliotecas e Informação. SiBI em números: dados 
consolidados 2014b. Disponível em < http://www.sibi.ufrj.br/panorama/sibidados-condensados.pdf $>$. Acesso em: mar. 2016.

VERGUEIRO, Waldomiro; CARVALHO, Telma de. Indicadores de qualidade em bibliotecas universitárias brasileiras: $\mathrm{o}$ ponto de vista dos clientes. Perspect.

cienc. inf., Belo Horizonte, v. 6, n. 1, p. 27 - 40, jan./jun.2001. Disponível em: http://portaldeperiodicos.eci.ufmg.br/index. php/pci/article/viewFile/435/245>. Acesso em: 24 jan. 2015.

1 Artigo produzido a partir da dissertação Mídias sociais nas bibliotecas da UFRJ: adoção e monitoramento. Disponível no link: http://www.unirio.br/ppgb/arquivo/claudia-regina-dos-anjos, no trabalho é possível ter acesso ao Manual Básico de Uso de Mídias Sociais um material adicional direcionado aos profissionais da informação, onde são apresentadas sugestões para uso, monitoramento e medição do desempenho organizacional na comunicação em mídias sociais. Esse produto foi criado para atender a demanda dos profissionais respondentes que declaram não estar habilitados para avaliar a presença de suas bibliotecas nas mídias sociais. 